\title{
Trichoadenomas of bilateral external auditory canals: a case report introduction
}

\section{Introduction}

Trichoadenoma is slow-growing tumor from hair follicles and it was described by Nikolows in $1958 .{ }^{1}$ Both trichoadenoma and desmoplastic trichoepithelioma are composed of cords of epithelial cells and cornifying cysts embedded in sclerotic stroma. In trichoadenoma the cystic component predominates. ${ }^{2}$

Trichoadenoma is found mostly in adults. Trichoepitheliomas are uncommon tumours which develop from undifferentiated germinative cells of the follicular-sebaceous-apocrine unit. The clinical appearance of trichoadenoma can be misleading, suggesting a diagnosis of basal cell carcinoma, seborrheic keratosis or epidermal cyst. ${ }^{2}$ Here we share 57 years old male patient has lesions bilaterally on both external auditory canals. Taken histopathology is diagnosed as Trichoadenoma.

\section{Case presentation}

57 -year-old male patient complaining with hearing loss refers to the Ear Nose Throat (ENT) clinic. In his ENT examination it wasn't found any pathology and nodular lesions were seen in his external auditory meatus. He described he has these lesions approximately one year. The hearing loss of the patient was thought to be related to the obstruction of the lesions in the external auditory canals. ENT clinic referred to patient to dermatology department.

During dermatology examination; one nodular $1 \times 1 \mathrm{~cm}$ skincolored lesion at right side of external auditory canal (Figure 1) and one nodular $1 \times 2 \mathrm{~cm}$ skin-colored lesion at left side of external auditory canal was observed (Figure 2) and punch biopsy was taken from each of the lesions.

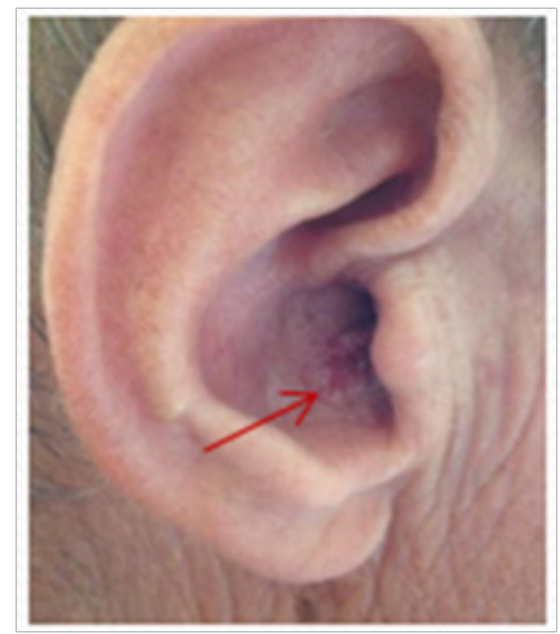

Figure I One nodular $|x| \mathrm{cm}$ skin-colored lesion at right side of external auditory canal.

The patient's biochemical analysis and internal studies did not reveal any systemic disease. Pathology reports described; tumour
Volume 2 Issue 2 - 2018

\author{
Zahide Eris Eken \\ Department of Dermatology, Istanbul Bilim University, Turkey
}

Correspondence: Zahide Eris Eken, Department of

Dermatology, Istanbul Bilim University, Gayrettepe Florence Nightingale Hospital, Istanbul, Turkey, Tel +902I 2288 3400, Email zahide.eris@istanbulbilim.edu.tr

Received: January 28, 2018 | Published: March 21, 2018

form full of pilar cyst which standing back to back with benign infundibulary style squamous epithelium under the superficial epithelium (Figure 3). Appearance of tumour composed of several pilar cysts with keratinized material in their lumens (Figure 4).

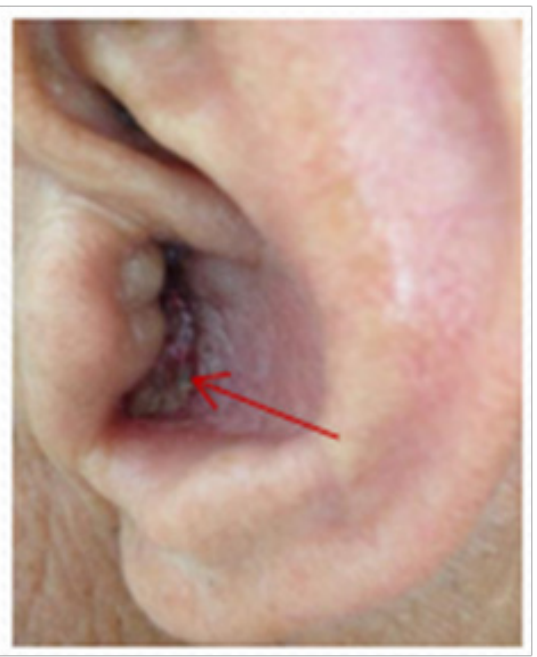

Figure 2 One nodular $1 \times 2 \mathrm{~cm}$ skin-colored lesion at left side of external auditory canal.

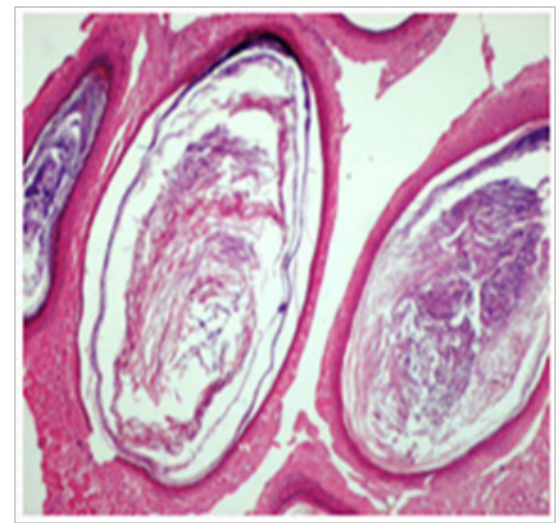

Figure $3 \mathrm{X}_{40}, \mathrm{H} \& \mathrm{E}$. Tumour form full of pilar cyst which standing back to back with benign infundibulary style squamous epithelium under the superficial epithelium. 


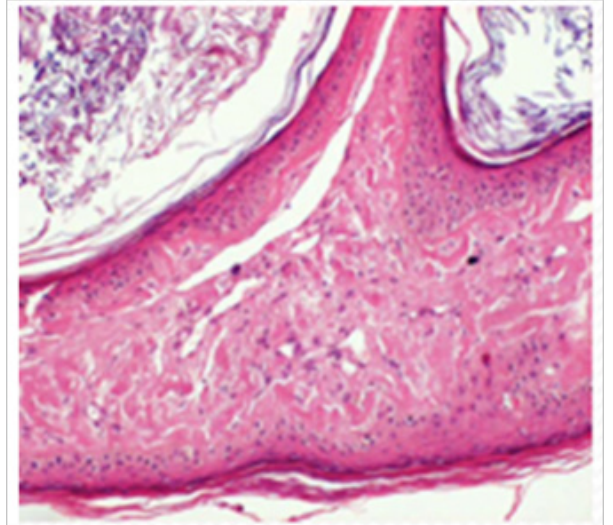

Figure $4 \mathrm{X}_{100}, \mathrm{H} \&$ E. Appearance of tumour composed of several pilar cysts with keratinized material in their lumens.

\section{Discussion}

Trichoadenoma often seen on the face and buttocks. ${ }^{2}$ Trichoadenomas are morphologically similar to Trichofoliculoma and trichoepithelioma ${ }^{3}$ the differential diagnosis for Trichoadenoma are basal cell carcinoma, epidermal cysts ${ }^{2}$ and it's also macroscopically similar to the Seborrheic Keratosis. Seborrheic keratosis histopathology is clear. It is tend to be sharply demarcated from the adjacent epidermis. Often exuberant keratin production occurs at the surface of seborrheic keratosis, and small keratin-filled cysts and cystic keratin-filled down growths from the surface of the lesion into the main tumor mass are characteristic features.

Trichoadenoma (Nikolowski) histologically corresponds to a well-circumscribed, horizontally oriented, dermal nodule, with no continuity with the overlying epidermis. The tumor is composed of numerous, relatively large, round or oval, infundibulocystic structures, separated by a poorly developed fibrous stroma. Trichoepithelioma; as trichoadenoma, it is a horizontal intradermal well-defined tumor composed of keratinous infundibulocysts depicting granular layer. However, nests of germinative cells in nodular, trabecular and cribriform arrays coexist in different proportions. Also, contrasting with trichoadenoma, follicular germ, papillar or bulb differentiation and retraction clefts within the stroma are characteristically seen in trichoepithelioma.

In trichofolliculoma, sections show numerous small follicles radiating from a central larger follicle. The hairs are surrounded by a well circumscribed dense stroma. The surrounding hairs are generally very small. Intermixed Merkel cells and sebocytes may be seen. ${ }^{4}$
Some authors think that this neoplasm is a desmoplastic trichoepithelioma variant. They have similar features by light microscopy analysis. ${ }^{5}$ Based on the above histopathology informations; we diagnosed the lesions as trichoadenomas. In literature there is a few case reports about trichoadenoma in rare sites (eyelid, upper lip, vulva). ${ }^{6-8}$ Matos and Linthicum describe a case of trichoadenoma of the external auditory canal. ${ }^{4}$ We did not find a systemic disease associated with bilateral trichoadenomas in the literature review.

We want to share 57 years old patient each of bilateral external auditory meatus filled with keratinize and nodular lesions and histopathologically identified trichoadenomas. This is first literature case of trichoadenomas that seen bilateral external auditory canals.

\section{Acknowledgements}

None.

\section{Conflicts of interest}

The authors declared that there are no conflicts of interest.

\section{References}

1. Nikolowski W. Trichoadenoma. Arch Klin Exp Dermatol. 1958;207(1):34-35.

2. Reibold R, Udeutch W, Fleiner J. Trichoadenoma of Nikolwski Review of four decades and seven new cases. Hautartz. 1998;49(12):925-928.

3. Shimanovich I, Krahl D, Rose C. Trichoadenoma of Nikolowski is a distinct neoplasm within the spectrum of foliculer tumors. $J$ Am Acad Dermal. 2010;62(2):277-283.

4. Tellechea O, Cardoso JC, Reis JP, et al. Benign follicular tumors. An Bras Dermatol. 2015;90(6):780-796.

5. Matos TO, Linthicum FH. Trichoadenoma of the external auditory canal. Otol Neurotol. 2011;32(9):e36-e37.

6. Lever JF, Servat JJ, Nesi Eloff F, et al. Trichoadenoma of an eyelid in an adult mimicking sebaceous cell carcinoma. Ophthal Plast Reconstr Surg. 2012;28(4):e101-e102.

7. Bombeccari GP, Guzzi G, Mariani U, et al. Trichoadenoma of the upper lip. Stomatologija. 2015;17(3):102-104.

8. Sangwaiya A, Bairwa S, Kalhan S, et al. Trichoadenoma of NikolowskiA Rare Tumour with Unusual Presentation Over Vulva. J Clin Diagn Res. 2017;11(1):ED05-ED06. 